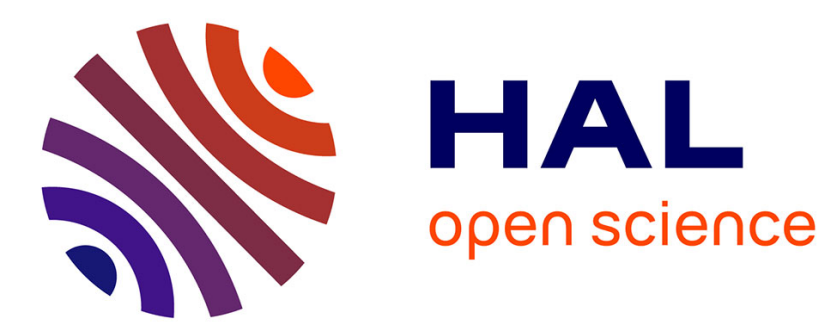

\title{
2D Multilayer solution for an electrified road with a built-in charging box
}

\author{
Armelle Chabot, Pawan Deep
}

\section{To cite this version:}

Armelle Chabot, Pawan Deep. 2D Multilayer solution for an electrified road with a builtin charging box. Road Materials and Pavement Design, 2019, 20 (sup2), pp.S590-S603. 10.1080/14680629.2019.1621445 . hal-02152802

\section{HAL Id: hal-02152802 \\ https://hal.science/hal-02152802}

Submitted on 11 Jun 2019

HAL is a multi-disciplinary open access archive for the deposit and dissemination of scientific research documents, whether they are published or not. The documents may come from teaching and research institutions in France or abroad, or from public or private research centers.
L'archive ouverte pluridisciplinaire HAL, est destinée au dépôt et à la diffusion de documents scientifiques de niveau recherche, publiés ou non, émanant des établissements d'enseignement et de recherche français ou étrangers, des laboratoires publics ou privés. 


\title{
2D Multilayer Solution for an Electrified Road with a built-in Charging Box
}

\author{
Armelle Chabot ${ }^{1}$, Pawan Deep ${ }^{2}$ \\ ${ }^{1}$ IFSTTAR, CS5004, F-44344 Bouguenais Cedex, France, corresponding author: \\ armelle.chabot@ifsttar.fr \\ ${ }^{2}$ Copenhagen, Denmark
}

\begin{abstract}
Charging electric vehicles inductively as they are being driven on the road is a conceivable option through a prefabricated charging box placed underneath the top asphalt layer of existing flexible pavements. Such a box inclusion however generates a material discontinuity in the pavement layer and points of singularities, inducing failure in the materials involved under heavy moving loads. To design such an electrified road, the specific model proposed here yields parametric calculations of multilayered structures embedded in a crack. By separating the problem into multiple zones across different material layers in a cross-sectional geometry, the multilayered solution presented provides all the mechanical fields and interface stresses between layers. On an electrified road case study from the literature, a vertical crack between box and material layer extends applicability of this mechanical solution to predicting failures like layer debonding. An alternative top pavement layer material is suggested for future developments.
\end{abstract}

Keywords: eRoads, Discontinuities, Cracks, Modelling, M4-5nW

\section{Introduction}

To achieve a reduction in $\mathrm{CO} 2$ emissions in meeting the European Energy Agency objectives for 2050, one of the solutions proposed is the electrified Roads (referred to as eRoad) (Rim, 2013; Fisher et al., 2014; Pérez et al., 2016). To inductively charge the moving Electric Vehicle (EV), one idea calls for inserting a prefabricated Charging Unit $(\mathrm{CU})$ into a top asphalt layer of the existing flexible pavement. It is then proposed to cover the entire structure with a thin layer that is also made of an asphalt material (Figure 1). The adaptation of eRoads is considered as a potential innovative solution. Nevertheless, the material and pavement structures offering acceptable charging solutions must be analysed in further detail. To be valid, this solution would in particular need to ensure a good bond between all the various materials in order to improve the durability of such pavements (Petit et al., 2018a, 2018b).

This proposed prefabricated CU had originally been designed using a cement concrete material (Nguyen et al., 2014; Pérez et al., 2016; Chen et al., 2017), thus introducing a major material discontinuity in the existing asphalt layers capable of causing a poor bond between the two materials (Deep, 2017). The ratio of the modulus between these two distinct materials in the charging box and layer accommodating the $\mathrm{CU}$ creates a tremendous singularity that depends on: environmental conditions, lateral vehicles displacements during lane-changing, and vehicle speed. This singularity worsens when the vehicle accelerates or is decelerates (Hammoum et al., 2010). In the following discussion, such lateral wandering will be denoted "w", in accordance with the notation adopted by Chen et al. (2017) (see Figure 1). A zero "w" value means that 
the vehicle loads are located at a symmetrical distance from the edge box. Such a vertical discontinuity, along with the interface discontinuity between box and materials, has not yet been fully studied (Chabot and Deep, 2018; Chen et al., 2018). To consider the material discontinuity due to inclusion of the box in asphalt overlays, a new development has been introduced in a 2D specific tool, called M4-5nW (Nasser and Chabot, 2015, 2018). The M4-5nW tool is based on an advanced model, i.e. M4-5n, for use with the Multi-Particle Model of Multilayer Materials (M4) containing 5n of equilibrium equations (n: total number of layers) (Chabot, 1997) and with Winkler springs (W). This 2D M4-5nW tool allows for convenient parametric calculations (Chabot and Nasser, 2015). In accordance with Deep (2017) and Chabot and Deep, (2018), this paper presents the main results of a new development in the M4-5nW tool that allows considering a material discontinuity in one or several material layers in order to analyse such discontinuities in an eRoad built with a prefabricated Charging Unit (CU) inclusion in the existing asphalt pavements. Applied to a cross-sectional geometry and material case study undertaken Chen et al. (2017), this tool makes available to engineers working on a pavement case study an alternative pavement structure suitable for further testing by means of full-scale accelerated experiments.

\section{The M4-5nW approach to modelling a pavement with cracks}

The simplified approach, chosen to study discontinuities in pavements, uses Winkler springs (W) to model one part of the soil foundation plus the M4-5n, which has been specially designed to analyse delamination in multilayered systems under bending loads (Chabot, 1997). The M4-5n belongs to the family of Multi-Particle Models of Multilayer Materials (M4), in which one M4 layer, with index i $\epsilon\{1, n\}$, represents a single real layer or an equivalent combination of several physical layers or any other

layer thickness needed to ensure the accuracy and reduced time consumption of the final solution. The M4-5n construction itself is based on a polynomial approximation per layer in $\mathrm{z}$ for the in-plane stress fields (where $\mathrm{x}$ and $\mathrm{y}$ denote the coordinates of the plane of the layers and $z$ denotes the vertical coordinate, see Figure 2). The coefficients of these polynomial approximations are expressed via Reissner's classical generalized stress fields per layer $\mathrm{i}$. The shear and normal stresses, denoted respectively $\tau_{\alpha}^{i, i+1}(x, y)$ and $v^{\mathrm{i}, \mathrm{i}+1}(x, y)$ at the interface between layers $\mathrm{i}$ and $\mathrm{i}+1$ (similarly $\mathrm{i}-1$ and $\mathrm{i}, \mathrm{i} \in\{1, \mathrm{n}-1\}, \alpha$ $\epsilon\{1,2\})$, ensure the continuity between these two consecutive layers through Equation (1).

$$
\left\{\begin{array}{l}
\tau_{\alpha}^{i, i+1}(x, y)=\sigma_{\alpha 3}\left(x, y, h_{i}^{+}\right)=\sigma_{\alpha 3}\left(x, y, h_{i+1}^{-}\right) \\
v^{\mathrm{i}, \mathrm{i}+1}(x, y)=\sigma_{33}\left(x, y, h_{i}^{+}\right)=\sigma_{\alpha 3}\left(x, y, h_{i+1}^{-}\right)
\end{array}\right.
$$

where $h_{i}^{+}$and $h_{i}^{-}$are the coordinates of the upper and lower face of layer i respectively. The thickness, denoted $e^{i}$, of each layer $\mathrm{i}$ is then $e^{i}=h_{i}^{+}-h_{i}^{-}$.

Each i layer has its own behavioural laws, equilibrium equations and lateral boundary conditions. A vertical crack is easy to introduce into each layer separately (Chabot et al., 2005, 2007). This model can be viewed as a the superimposition of $n$ Reissner plates linked by interfacial forces; it reduces the real 3D problem to the determination of plane fields $(x, y)$ for each layer $i$ and at the interface $i, i+1$, (and $i-1$, i). Thus, the real 3D (2D) object is transformed into a 2D (1D) geometry. This approach leads to the development of delamination criteria and semi-analytical calculations without encountering any of the singularity type problems of interface stresses (Chabot, 1997; Caron et al., 2006; Chabot et al., 2013). 
For pavement applications, the M4-5n layer numbering starts at the surface layer, as shown in the general diagram (Figure 1). In the so-called M4-5nW tool developed for 2D plane strain problems (Nasser and Chabot, 2015, 2018), the pavement is set as the equivalent of 3 material layers resting on the soil. The soil is assumed equivalent to a combination of a dummy layer ("shear soil layer" no. 4), thus ensuring the transfer of shear stresses between the pavement multilayer and Winkler springs (Figure 2). In this case, a series of M4-5nW equation operations leads to writing a $12 \times 12$ second-order differential system of analytical equations that depend solely on variable $\mathrm{x}$ (Equation 2):

$$
\mathrm{AX}^{\prime \prime}(\mathrm{x})+\mathrm{BX}^{\prime}(\mathrm{x})+\mathrm{CX}(\mathrm{x})=\mathrm{DY}^{0,1^{\prime}}(\mathrm{x})+\mathrm{EY}^{4,5^{\prime}}(\mathrm{x})+\mathrm{FY}^{0,1}(\mathrm{x})+\mathrm{GY}^{4,5}(\mathrm{x})
$$

with the first order M4-5nW unknowns written as follows (Equation 3):

$$
[X]=\left[\begin{array}{c}
X^{1} \\
\vdots \\
X^{n}
\end{array}\right]_{3 n \times 1} ;[X]=\left[\begin{array}{c}
U_{1}^{i} \\
\phi_{1}^{i} \\
U_{3}^{i}
\end{array}\right] ;\left[Y^{0,1}\right]=\left[\begin{array}{c}
\tau^{0,1} \\
v^{0,1}
\end{array}\right]_{2 \times 1} ;\left[Y^{n, n+1}\right]=\left[\begin{array}{c}
\tau^{n, n+1} \\
v^{n, n+1}
\end{array}\right]_{2 \times 1} i \in[1,4]
$$

where $U_{1}^{\mathrm{i}}(x), U_{3}^{\mathrm{i}}(x)$ and $\phi^{i}(x)$ are, respectively, the average in-plane displacements, average out-of-plane displacements and average rotations of the layer $\mathrm{i}(i \in[1,4])$. The matrices $[\mathrm{A}]_{12 \times 12},[\mathrm{~B}]_{12 \times 12},[\mathrm{C}]_{12 \times 12},[\mathrm{D}]_{12 \times 2},[\mathrm{E}]_{12 \times 2},[\mathrm{~F}]_{12 \times 2}$ and $[\mathrm{G}]_{12 \times 2}$ of the above system (2) that depend solely on the geometric and mechanical parameters of the equivalent elastic problem. These matrices have been given analytically by Nasser and Chabot (2018).

The indices "0,1" and "4,5" are used for the boundary conditions respectively at the top of the pavement, between the outside and the first layer, and at the bottom of the multilayer, between the outside and the fourth layer, where it provides the connection between the shear layer and the Winkler foundation. The spring stiffness computation uses Odemark's formula (Odemark, 1949). In considering $E^{s}$ as the Young's modulus of the soil, the hypothesis of a continuity of critical displacements between the multilayers and the Winkler mass is implied by the boundary conditions binding the interface forces and the springs, as written in Equation (4).

$$
\left\{\begin{array}{c}
\tau_{1}^{4,5}(x)=0 \\
v^{4,5}(x)=-k U_{3}^{4}(x)
\end{array} \text { with } k=\frac{E^{S}}{h^{*}} \text { and } h^{*}=\sum_{i=1}^{i=4} f e^{i^{3}} \sqrt{\frac{E^{i}}{E^{S}}}\right.
$$

where $\mathrm{f}$ is a correction factor which is equal to 0.83 for a multilayer.

Following the initial M4-5n works for a pavement with existing vertical cracks (Tran et al., 2004; Chabot et al., 2005) and as explained in Nasser and Chabot (2015, 2018), the 2D tool semi-analytically solves Equation (2) using the Newmark discretization presented in Equation (5).

$$
\frac{X_{j+1}^{\prime}+X_{j}^{\prime}}{2}=\frac{X_{j+1}+X_{j}}{k_{j+1}} ; k_{j+1}=x(j+1)-x(j)
$$

Next, thanks to the definition of the M4-5n generalised displacements and the M4-5n generalised stresses (Chabot, 1997), it is possible to derive the M4-5n approximate displacements and M4-5n approximate stress fields through the entire 2D plane. 


\section{Numerical development in the M4-5nW tool for an eRoad type analysis}

To test whether the M4-5nW would be a convenient tool for the parametric study of prefabricated CU inclusions in roads with possible macrocracks between materials, in the case of highly different materials being used, it is proposed herein to analyse the elastic stress distribution around the charging box for the 2D plane strain example of Chen's PhD works (Chen et al., 2017). In that case study, as illustrated in Figure 1 and studied in Section 4, the proposed CU is made of a cement concrete material and inserted into an existing flexible pavement. Owing to problem symmetry, only half the cross geometry of Figure 1 will be studied (Figure 2). The M4-5nW problem can thus be divided into four zones (Deep, 2017).

The moving load conditions are written in Zone 3, where $\mathrm{x} \in\left[l_{b}+l_{w}, l_{b}+l_{w}+\right.$ $\left.l_{F}\right]$ (Figure 2). In that Zone 3, the load $\mathrm{q}(\mathrm{x})$, which describes the vertical and uniform load distribution from the tyre contact, is in the downward $\mathrm{z}$ direction. The boundary condition at the upper interface $(0,1$ index) can then be written into the following Equation (6).

$$
\left\{\begin{array}{c}
\tau_{1}^{0,1}(x)=0 \\
v^{0,1}(x)=\mathrm{q}(x)
\end{array} \mathrm{x} \in\left[l_{b}+l_{w}, l_{b}+l_{w}+l_{F}\right]\right.
$$

In a subsequent development (Tran et al., 2004; Chabot et al., 2005), the M4-5n boundary conditions at $x=0$ and $x=1$ describing the fixed boundary on the both ends (Figure 2), are provided through Equation (7):

$$
\left\{\begin{array}{c}
U_{1}^{i}(0)=U_{1}^{i}(l)=0 \\
\phi_{1}^{i}(0)=\phi_{1}^{i}(1)=0 \\
\left\{\begin{array}{l}
\phi_{1}^{i} 0+U_{3,1}^{i}(0)+\frac{1+\vartheta^{i}}{5 E^{i}}\left(\tau_{1}^{i-1, i}(0)+\tau_{1}^{i, i+1}(0)\right)=0 \\
\phi_{1}^{i}(l)+U_{3,1}^{i}(l)+\frac{1+\vartheta^{i}}{5 E^{i}}\left(\tau_{1}^{i-1, i}(l)+\tau_{1}^{i, i+1}(l)\right)=0
\end{array}\right.
\end{array}\right.
$$

$A$ " $b$ " index notation, for the points of layers 2 and 3 containing the box inclusion, will be used in the following.

\subsection{Adaptation of the M4-5nW equations for eRoad problems with built-in CU}

The first additional zone I introduced in the M4-5nW tool pertains to the CU location, where $\mathrm{x} \in\left[0, l_{b}\right]$. This CU inclusion is placed in the layers nos. 2 and 3 of the multilayered structure (Figure 2).

Since the CU box is made of a different material than the layer material, the matrices of both Zone 1 (box zone $\left(x \in\left[0, l_{b}\right]\right)$ ) and those outside the box zone $\left.\left(x \in\left[l_{b}, l\right]\right)\right)$ differ in the second-order differential system of the 12 analytical equations function of (x) (Equation 2). This system is modified for Zone 1 as written in Equation (8) below:

$$
A^{b} X^{\prime \prime}(x)+B^{b} X^{\prime}(x)+C^{b} X(x)=D^{b} Y^{0,1^{\prime}}(x)+E^{b} Y^{4,5^{\prime}}(x)+F^{b} Y^{0,1}(x)+G^{b} Y^{4,5}(x)
$$

M4-5n is a projection of all these layers into a single system, hence modifications to the material properties in the two layers 2 and 3 for Zone $1\left(x \in\left[0, l_{b}\right]\right)$ (Figure 2), lead to different matrices even though their construction remains identical. 
Note that system is solved, for the geometric position of charging box for Zone 1 $\left(x \in\left[0, l_{b}\right]\right)$. Beyond Zone 1 , where $x \in\left[l_{b}, l\right]$, by taking the layer material into account, the process is repeated to obtain these matrices.

Once the analytical equations for Zones 1 and Zone 2 have been written, the continuity equations for displacement and rotations at $\left(x=l_{b}\right)$ are given in Equations (9), (10) and (11) as:

$$
\begin{aligned}
& U_{1}^{2 \mathrm{~b}}\left(l_{b}\right)=U_{1}^{2}\left(l_{b}\right) \text { and } U_{1}^{3 \mathrm{~b}}\left(l_{b}\right)=U_{1}^{3}\left(l_{b}\right) \\
& U_{3}^{2 \mathrm{~b}}\left(l_{b}\right)=U_{3}^{2}\left(l_{b}\right) \text { and } U_{3}^{3 \mathrm{~b}}\left(l_{b}\right)=U_{3}^{3}\left(l_{b}\right) \\
& \phi_{1}^{2 \mathrm{~b}}\left(l_{b}\right)=\phi_{1}^{2}\left(l_{b}\right) \text { and } \phi_{1}^{\mathrm{3b}}\left(l_{b}\right)=\phi_{1}^{3}\left(l_{b}\right)
\end{aligned}
$$

The two interfacial behaviour relationships at interface $\mathrm{i}, \mathrm{i}+1$ between layer $\mathrm{i}$ and layer $\mathrm{i}+1$, as given in Equations (12) and (13) (Chabot, 1997), are then used to derive the continuity relationship between the two interfacial unknowns present due to the material discontinuity in layers 2 and 3 .

$$
\begin{array}{r}
\frac{e^{i+1}}{12} U_{3,1}^{i+1}(x)+\frac{e^{i}}{12} U_{3,1}^{i}(x)+U_{1}^{i+1}(x)-U_{1}^{i}(x)-\frac{5 e^{i+1}}{12} \phi_{1}^{i+1}(x)-\frac{5 e^{i}}{12} \phi_{1}^{i}(x)= \\
-\frac{\left(1+v^{i}\right) e^{i}}{12 E^{i}} \tau_{1}^{i-1, i}(x)-\frac{\left(1+v^{i+1}\right) e^{i+1}}{12 E^{i+1}} \tau_{1}^{i+1, i+2}(x)+\left(\frac{\left(1+v^{i}\right) e^{i}}{4 E^{i}}+\frac{\left(1+v^{i+1}\right) e^{i+1}}{4 E^{i+1}}\right) \tau_{1}^{i, i+1}(x)(12) \\
U_{3}^{i+1}(x)-U_{3}^{i}(x)=\frac{9}{70} \frac{e^{i}}{E^{i}} v^{i-1, i}(x)+\frac{9}{70} \frac{e^{i+1}}{E^{i+1}} v^{i+1, i+2}(x)+\frac{13}{35}\left(\frac{e^{i}}{E^{i}}+\frac{e^{i+1}}{E^{i+1}}\right) v^{i, i+1}(x)(13)
\end{array}
$$

In subtracting Equation (13) at point $\mathrm{x}=\mathrm{l}_{\mathrm{b}}$ and using Equation (9), Equations (14) to (16) are obtained for the three interfaces affected by the presence of the CU (first between layers 1 and 2, then between layers 2 and 3 and lastly between layers 3 and 4) (Figure 2).

$$
\begin{gathered}
\frac{13}{35}\left(\frac{e^{1}}{E^{1}}+\frac{e^{b 2}}{E^{b 2}}\right) v^{b(1,2)}\left(l_{b}\right)+\frac{9}{70} \frac{e^{\mathrm{b} 2}}{E^{\mathrm{b} 2}} v^{b(2,3)}\left(l_{b}\right)=\frac{13}{35}\left(\frac{e^{1}}{E^{1}}+\frac{e^{2}}{E^{2}}\right) v^{1,2}\left(l_{b}\right)+\frac{9}{70} \frac{e^{2}}{E^{2}} v^{2,3}\left(l_{b}\right) \\
\frac{9}{70} \frac{e^{b 2}}{E^{b 2}} v^{b(1,2)}\left(l_{b}\right)+\frac{13}{35}\left(\frac{e^{b 2}}{E^{b 2}}+\frac{e^{b 3}}{E^{b 3}}\right) v^{b(2,3)}\left(l_{b}\right)+\frac{9}{70} \frac{e^{\mathrm{b} 3}}{E^{\mathrm{b} 3}} v^{b(3,4)}\left(l_{b}\right)= \\
\frac{9}{70} \frac{e^{2}}{E^{2}} v^{1,2}\left(l_{b}\right)+\frac{13}{35}\left(\frac{e^{2}}{E^{2}}+\frac{e^{3}}{E^{3}}\right) v^{2,3}\left(l_{b}\right)+\frac{9}{70} \frac{e^{3}}{E^{3}} v^{3,4}\left(x l_{b}\right) \\
\frac{13}{35}\left(\frac{e^{b 3}}{E^{b 3}}+\frac{e^{4}}{E^{4}}\right) v^{b(3,4)}\left(l_{b}\right)+\frac{9}{70} \frac{e^{\mathrm{b} 3}}{E^{\mathrm{b} 3}} v^{b(2,3)}\left(l_{b}\right)=\frac{13}{35}\left(\frac{e^{3}}{E^{3}}+\frac{e^{4}}{E^{4}}\right) v^{3,4}\left(l_{b}\right)+\frac{9}{70} \frac{e^{3}}{E^{3}} v^{2,3}\left(l_{b}\right)
\end{gathered}
$$

Similarly, by subtracting Equation (12), at $\mathrm{x}=\mathrm{l}_{\mathrm{b}}$ and then using Equations (9) to (11), a system of the three additional equations is obtained to assure the continuity of the interface shear stresses of the three interfaces involved (Deep, 2017).

The system can thus be solved numerically given that all the boundary, continuity and interface conditions have been formulated and defined for this eRoad inclusion problem.

\subsection{Numerical solution of the M4-5nW for the eRoad problem with $C U$ inclusion}

To solve this system numerically by means of the Finite Difference Method (FDM), the 
multilayered equivalent medium is discretized into $\mathrm{N}$ points in the $\mathrm{x}$-direction (Figure $3)$. Each point contains all the M4-5n mechanical fields of each layer i.

Introducing a change of material in one (or several) layer equations of the M4$5 \mathrm{nW}$ tool leads to modifying the initial equations of the differential system and FDM scheme with approximations around the changes of Zone 1 and 2 , at point $\mathbf{j} b\left(x=l_{b}\right)$

(Deep, 2017). Next, in considering the set-up in Figure 3 with fine meshes, the differential dimension of the problem written in Equation (2) can be reduced using twice the Newmark discretization given in Equation (5). This implementation has been performed for a uniform discretization.

Due to issues of separating the equations explicitly in M4-5n, the discretization is used as if at node $\mathbf{j}_{\mathrm{b}}$ both the materials are glued with infinite strength. According to M4-5n developments using FDM (Tran et al., 2004), this fast and approximate method leads to a numerical solution of a system of $12 \mathrm{~N}$ equations as summarized in Equation (17).

$$
\mathbb{A} \mathbb{X}(x)=\mathbb{B} \mathbb{Y}^{0,1}(x)+\mathbb{C} \mathbb{Y}^{n, n+1}(x)
$$

Now having the primary displacement field unknowns after solving this primary system, it is thus necessary to calculate the secondary unknowns linked to the main M4$5 \mathrm{n}$ stress fields defined for each layer $\mathrm{i}$. The functions calculating derivatives are also modified to handle the material discontinuity. To calculate the interface unknowns, the functions are used separately for Zones 1 and 2 and then combined selectively for both these zones.

\subsection{Introduction of vertical debonding between the $C U$ and a part of the asphalt layer}

In addition, depending on the chosen bonding case, as illustrated in section 4, the M4$5 \mathrm{nW}$ lateral boundary conditions must use a system of continuity (or discontinuity) equations written in terms of the generalised stresses and generalised displacements of layer 2 at point $\mathbf{j}_{\mathbf{b}}$ of the $\mathrm{CU}$ edge at point $\mathrm{x}=l_{b}$. A macro vertical crack is selected between Zone 1 and 2 in order to model the CU and asphalt layers. This separation is modelled by using the previously employed macro vertical crack in the layer (Chabot et $a l ., 2007)$, where the system on both the left and right slides of the crack introduced into that layer are already numerically uncoupled. Using a thin discretization, the M4-5n boundary conditions of free edges are written between two consecutive nodes (Figure 4).

Index f represents the crack, thus a vertical crack exists in the layers next to the box; for this application, such is the case only for the layers with the box and stresses around this position (i.e. the separate points $X_{f}$ and $X_{f+1}$ ). They can be expressed as follows (Equation (18)).

$$
\left\{\begin{array} { l } 
{ N _ { 1 1 } ^ { 2 } ( X _ { f } ) = 0 } \\
{ M _ { 1 1 } ^ { 2 } ( X _ { f } ) = 0 } \\
{ Q _ { 1 } ^ { 2 } ( X _ { f } ) = 0 }
\end{array} \text { and } \quad \left\{\begin{array}{c}
N_{11}^{2}\left(X_{f+1}\right)=0 \\
M_{11}^{2}\left(X_{f+1}\right)=0 \\
Q_{1}^{2}\left(X_{f+1}\right)=0
\end{array}\right.\right.
$$

where $N_{11}^{i}, M_{11}^{i}$ and $Q_{1}^{i}$ are the secondary unknowns of the normal stress component along $\mathrm{x}$, the moment component along $\mathrm{x}$ and the shear force of layer i respectively. This development allows for the different material modulus values to be used to the left of the crack, in the M4-5nW, in one of the layers initially containing the box. This set up 
also allows the box to be located in two layers and a different material next to the box in both the layers including the crack. The above scheme can be easily extended to any number of layers, hence multiple combinations of different materials can be used to model the desired application with respect to both the chosen CU thickness and the material in the layer adjacent to the CU.

\section{Results and alternative eRoad structure proposal}

To study the rutting effect in such an eRoad, an all viscoplastic behavioural law with coupled damage for asphalt layers can be employed (Chen et al., 2017). This set-up leads to the determination of many unknowns and makes use of considerable number of parameters in a structural tool. The present analysis focuses more on the effects of a possible macrocrack existing in such an eRoad. An elastic model is assumed to be acceptable with equivalent modelling assumptions at a given temperature and load speed (Chupin et al., 2014) (Bodin et al., 2017).

First, the geometry, the load and the elastic material characteristics of the pavement studied in this paper are chosen so as to obtain the similar asphat pavement results to those of Chen et al. (2017). A uniformly distributed load of $800 \mathrm{kPa}$, among a tyre width of $0.20 \mathrm{~m}$, is applied. In that paper, the equivalent elastic material of the first asphalt layers fitting Chen's results, as derived in section 4.1 , is assumed to be representative of a standard material, called BBSG for "Béton Bitumineux Semi Grenu" (a European material provided from the standard NF EN 13108-1, 2008). According to the French design method (Corte and Goux, 1997), for all results presented below, the corresponding modulus value is assumed to be representative of the common average vehicle speed proposed in the method, i.e. an average vehicle speed of $72 \mathrm{~km} / \mathrm{h}$. Next, in Section 4.2, the mechanical field with or without the presence of CU vertical debonding, in light of the proposed cement concrete composition, and the existing asphalt layer will be studied. For all the calculations, a regular mesh is used with 20 such meshes applied to Zone 1 (Figure 3). According to the modelled case (Figure 1), this implies a mesh width of $20 \mathrm{~mm}$ been kept for all simulated zones and all cases studied.

\subsection{Validation of the new tool and determination of the equivalent elastic material of layer1}

In an effort to validate the new M4-5nW numerical set-up that considers a CU inclusion (with or without macrocracks), in assuming the non-realistic case of a CU inclusion made of the same material as the host asphalt layers, an initial parametric study leads to determining the equivalent elastic asphalt Young's modulus of the asphalt layers. According to Chen's data, Layer 4 is supposed to be made of an equivalent unbound granular material. For the M4-5nW study and in respecting a ratio of no greater than 4 between each layer thickness (Tran et al., 2004; Nasser and Chabot, 2018), the layer characteristics obtained for this flexible pavement are listed in Table 1. The soil model has been adapted accordingly with $E^{\mathrm{s}}=160 \mathrm{MPa}$ in Equation (4).

Figure 5 illustrates the new numerical implementation of the CU inclusion in the M4-5nW obtained for this case (with for M4-5nW a virtual CU inclusion having the same Young's modulus as the asphalt layers). The equivalent Young's Modulus value obtained is $E^{1}=E^{2}=E^{3}=1000 \mathrm{MPa}$ (Figure 5). This very low modulus value could correspond to a standard European asphalt material (BBSG) set at $40^{\circ} \mathrm{C}$ at an average 
speed of $72 \mathrm{~km} / \mathrm{h}$ as mentioned above. The resulting curves in Figure 5 successfully lie in the same range of values as the results given by Chen with the use of a viscoelastic model of the asphalt layers (Chen et al., 2017).

\section{2 eRoad structure proposal regarding both material and pavement}

For the eRoad under study, the prefabricated CU (height $e=0.14 m$, width $2 l_{b}=$ $0.8 \mathrm{~m}$ ) is assumed to generate $30 \mathrm{GPa}$ with a Poisson's ratio of 0.2 . This $\mathrm{CU}$ inclusion, made of cement concrete, is placed into the layers 2 and 3 of the pavement structure, as illustrated in Figure 3 and with the layer materials given in Table 1. In the following discussion, considering that the worst case for bonding is when the load is located as closed as possible to the vertical cracks as shown in Nasser and Chabot (2018). Figure 6 illustrate Chen's case of a lateral wandering value equal to -0.2 (Chen et al., 2017), i.e. when the load is near the CU edge. In the case of a perfect bond between the CU and asphalt layers, as illustrated by the Von Mises curves in Chen et al. (2017) and with the following M4-5nW $\sigma_{z z}(x, z)$ distribution, the bond between the CU and asphalt material may indeed be affected due to the change of materials in Layers 2 and 3 around $x=l_{b}$ (Figure 6).

With help of this new M4-5nW tool and in considering a scenario where the bonding conditions have failed between the $\mathrm{CU}$ and asphalt layers due to the very high modulus ratio between the cement concrete material of the box and asphalt layers at $40^{\circ} \mathrm{C}$, a vertical macrocrack over the entire thickness of Layers 2 and 3 is introduced. According to M4-5n theory, only zero stress conditions at $i$ index values of 2 and 3 (for the concerned layers 2 and 3 ) are applied at the $\mathbf{j}$ b point (Figure 3). That case is illustrated in the following discussion for two load positions (Figure 8 and 9).

Next, in considering that the thick layer of the asphalt pavement (Layers 2 plus 3 , modelled by M4-5nW as illustrated in Figure 2) was likely to have originally been built with two asphalt sub-layers a perfect bond may no longer exist between the layers or else it may be damaged. Consequently, from the latest international RILEM knowledge on cracking and debonding in asphalt composite and pavement structures (Buttlar and Chabot, 2018), an alternative eRoad structure is ultimately proposed for the case under study. It is being suggested that engineers test the option by first removing half of the existing thick asphalt layer (here, Layer 2 in Figure 2) before placing the CU made of cement concrete material in the remaining half-layer (i.e. Layer 3) (Figure 7). It should then become possible to cast and cover the entire arrangement with a cement concrete (for Zones 2 to 4 of Layer 2 and Layer 1 as noted on Figure 2), as commonly used for Ultra-Thin Whitetopping pavement (Rasmussen et al, 2004).

These inverse composite pavements featuring a cement concrete overlay mix cast directly onto an existing asphalt pavement, have demonstrated their efficiency in terms of the interlayer bond (Chabot et al., 2008, 2013; Vandenbossche and Barman 2010) even if thermal gradients and water may affect them (Chabot et al., 2017; Mateos et al., 2017; Petit et al., 2018b). For this new pavement structure, the M4-5nW tool leads to considering the proposed multilayered system in Figure 7 where the cement concrete (CC) layer is virtually divided into Layers 1 and 2 for all zones except Zone 1. In this case, the $\mathrm{CU}$ is located both in the existing sub-asphalt layer no. 3 and the new sub CC-layer no. 2. The CC layers are assumed to display the same cement material characteristics as the CU. Naturally, if necessary, this parameter is easy to change in the M4-5nW tool.

In considering vertical debonding between the box and the asphalt Layers 2 and 3 , Figure 8 illustrates, even for a load position relatively far from the $\mathrm{CU}$ inclusion (for 
the lateral wandering position $\mathrm{w}=0$ ), the tremendous variation in interfacial normal stress $v^{1,2}(x)$ (Equation 1 without a y variable for the 2D problem studied here) between Layers 1 and 2 obtained in the initial case (called BBSG BBSG - crack), in comparison with the proposed alternative pavement case (called CC + BBSG).

As summarized in the paper with M4-5nW results, for each structure proposal, Figure 8 and 9 illustrate that the closer the load to the box (with $w=-0.2$ ), the higher the intensity of the interfacial normal stresses. The composite structure proposal $(\mathrm{CC}+\mathrm{BBSG}$ curves at the interfaces between Layers 1 and 2 and between Layers 2 and 3 ) reduces the interfacial normal stress intensity between layers 1 and 2 around the $C U$ edge (Figure 6). Even though, in this case, a small concentration of interfacial normal stress exists at the CU edge, this alternative structure offers an attractive solution for adapting the existing flexible pavements into an eRoad. In fact, for the final survey and maintenance of existing cables connecting the $\mathrm{CU}$ to the pavement side, where electricity needs to be re-injected, a small propagation of debonding near the joint of Ultra-Thin Whitetopping pavements may have occurred after several loading cycles (Chabot et al., 2008). This would therefore provide a good opportunity to access the cable position should it be located close to these existing joints.

Regardless of the actual pavement structure solution proposed, the presence of these cables must be carefully studied since it can be assumed that any such presence may also adversely affect the durability of asphalt pavements with, for instance, probable reflective cracking phenomenon, thus prompting the need for appropriate maintenance.

\section{Conclusion and outlooks}

In order to adapt existing flexible pavement structures into an eRoad with a prefabricated inductive Charging Unit (CU) placed underneath the top asphalt layer, the behaviourial material problems to be solved include finding pavement structural solutions to avoid a possible debonding phenomenon between the $\mathrm{CU}$ inclusion and other pavement materials. This challenge may arise quickly and, under such conditions, become one of the major distress parameters to be taken into account to ensure the durability of such new road concepts. In this case, the use of M4-5nW simulations may be beneficial for conducting several parametric studies. To consider such a material discontinuity due to a box inclusion in asphalt overlays as studied in Chen's work (Chen et al., 2017), a new development has been achieved in the 2D specific M4-5nW tool developed by Nasser and Chabot (2018) and presented therein. The introduction of a change of material in one or more layers leads to modifying the second-order differential system of M4-5nW analytical equations as well as the FDM numerical scheme, with approximations around the CU edges in these layers. In considering the use of a CU made with cement concrete and surrounding vertical cracks, it has been shown in this paper that reducing the modulus ratio between the the prefabricated CU material and the top layers could provide a suitable option for avoiding failure between the various material overlays. The pavement structure option proposed herein constitutes a mix of cement concrete materials cast directly onto an asphalt material layer, as used for Ultra-Thin Whitetopping pavements. Alternatively, another material may also be anticipated for the CU.

To contribute to this energy transition period, this modelling quickly seeks to highlight, from a pavement point of view, whether some particular mix of materials between layers could offer an attractive option to be studied in greater detail and ultimately tested by means of accelerated loading facilities. To compare the results and 
investigate in greater depth the structural durability of such adapted eRoad pavement types, through for instance studying other potential partial debonding locations in the eRoad between layers, future M4-5n developments could subsequently be achieved and implemented using the mixed finite element method proposed in Nasser et al. (2018).

\section{References}

Bodin, D., Chupin, O., Denneman, E. (2017). Viscoelastic Asphalt Pavement Simulations and Simplified Elastic Pavement Models Based on an "Equivalent Asphalt Modulus" Concept. Journal of Testing and Evaluation, 45 (6), 18871895.

Buttlar W.G., Chabot A. (2018) Introduction. In Buttlar W.G., Chabot A., Dave E.V., Petit C., Tebaldi G. (Eds) Mechanisms of Cracking and Debonding in Asphalt and Composite Pavements. State-of-the-Art Report of the RILEM Technical Committee 241-MCD Series, 28, 1-32, Springer International Publishing, doi: 10.1007/978-3-319-76849-6_1

Caron J. F., Diaz Diaz A., Carreira R. P., Chabot A., Ehrlacher A. (2006). Multi-particle modelling for the prediction of delamination in multi-layered materials. Composites Science and Technology, 66 (6), 755-765.

Chabot A. (1997). Analyse des efforts à l'interface entre les couches des matériaux composites à l'aide de Modélisations Multiparticulaires des Matériaux Multicouches (M4) (Doctoral dissertation). Retrieved from https://tel.archivesouvertes.fr/tel-00197853

Chabot A., Tran Q. D., Ehrlacher A. (2005). A simplified modeling for cracked pavements. Bulletin des Laboratoires des Ponts et Chaussées (ISSN 1269-1496), (258-259), 105-120.

Chabot A., Tran Q. D., Ehrlacher A. (2007, June). A modeling to understand where a vertical crack can propagate in pavements. In A. Loizos, T. Scarpas, \& I. L. AlQadi (Eds). Proceedings of the International Conference on Advanced Characterisation of Pavement and Soil Engineering (CRC Press, 1, pp. 431440). Athens, Greece.

Chabot A., Pouteau B., Balay J. M., \& De Larrard F. (2008, June). FABAC Accelerated Loading Test of Bond between Cement Overlay and asphalt layers. I. Al-Qadi, T. Scarpas, \& A. Loizos, (Eds), Pavement Cracking. Proceedings of the 6th Int. RILEM Conf. on Cracking in Pavements (CRC Press, pp. 671-681, doi: 10.1201/9780203882191.ch65). Chicago, US.

Chabot A., Hun M., Hammoum F. (2013). Mechanical analysis of a mixed mode debonding test for composite pavements. Construction and Building Materials, 40, 1076-1087.

Chabot A., Hammoum F., Hun M. (2017). A 4pt bending bond test approach to evaluate water effect in a composite beam. European Journal of Environmental and Civil Engineering, 21(sup1), 54-69.

Chabot A., Deep P. (2018, June). 2D Multilayer Analysis of Electrified Roads with Charging Box Discontinuities. Paper presented at the 13th ISAP Conference on Asphalt Pavements, Fortaleza, Ceará, Brazil.

Chen F., Balieu R., Córdoba E., Kringos N. (2017). Towards an understanding of the structural performance of future electrified roads: a finite element simulation study. International Journal of Pavement Engineering. doi: $0.1080 / 10298436.2017 .1279487$ 
Chen F., Coronado C. F., Balieu R., Kringos N. (2018). Structural performance of electrified roads: A computational analysis. Journal of Cleaner Production, 195, 1338-1349.

Chupin O., Chabot A., Bodin D., Piau J.-M. (2014, June). Determination of an equivalent elastic system to a multilayer viscoelastic structure: application to the case of thick flexible pavement. R. Y. Kim (Ed), Asphalt Pavements. In Proceedings of the 12th ISAP conference (CRC Press, 1, 797-804. ISBN 9781138026933), Raleigh, NC, USA.

Corte JF, Goux MT (1996). Design of pavement structures: the French technical guide. Transport Research Report, 1539,116-124.

Deep P. (2017). Mechanical analysis of an eRoad discontinuities (Unpublished master's thesis. Ecole Centrale de Nantes (ECN), France.

Fisher T. M., Farley K. B., Gao Y., Bai H., Tse Z. T. (2014). Electric vehicule wireless charging technology: a state-of-t-art review of magnetic coupling systems. Wireless Power Transfer, 1(102), 87-96.

Hammoum F., Chabot A., St. Laurent D., Chollet H., Vulturescu B. (2010). Effects of accelerating and decelerating tramway loads on bituminous pavement. Materials and Structures, 43, 1257-1269.

Mateos A., Harvey J., Paniagua F., Liu A. F. (2017). Mechanical characterisation of concrete-asphalt interface in bonded concrete overlays of asphalt pavements. European Journal of Environmental and Civil Engineering, 21(supp 1), 43-53.

Nasser H., Chabot A. (2015, September). Two-Dimensional Software for Analysing Mechanical Fields in Elastic Cracked Pavements. J. Kruis et al. (Eds). In Proceedings of the 5th International Conference on Civil, Structural and Environmental Engineering Computing (Civil-Comp Press, Paper 214, ISBN 978-1-905088-63-8, doi:10.4203/ccp.108.214), Prague, Czech Republic.

Nasser H., Chupin O., Piau J. M., Chabot A. (2018). Mixed FEM for solving a plate type model intended for analysis of pavements with discontinuities. Road Materials and Pavement Design, 19 (3), 496-510.

Nasser H., Chabot A. (2018). A half-analytical elastic solution for 2D analysis of cracked pavements. Advances in Engineering Software, 117, 107-122.

Nguyen M.L., Hornych P., Kerzreho J.P., Perez S. (2014, September). Accelerated full scale test on prefabricated concrete slab pavement for electrical supply by induction of urban transport systems. Paper presented at the 12th International Symposium on Concrete Roads, Prague.

Odemark N. (1949). Investigations as to the Elastic Properties of Soils and Design of Pavements According to the Theory of Elasticity. Report 77, National Swedish Road and Traffic Research Institute, Linkoping, Sweden.

Pérez S., Nguyen M. L., Hornych P., Curran E. (2016, June). Implementing recharging inductive technology on heavy-duty pavement bringing unlimited autonomy to electrical vehicles. Presented at the 8th Int. RILEM Conf. MCD2016, W3: Roads of the future: towards durable and multi-functional infrastructures, Nantes, France. 2016 (https://mcd2016.sciencesconf.org/resource/page/id/15).

Petit C., Chabot A., Destrée A., Raab C. (2018a). Recommendation of RILEM TC 241MCD on Interface Debonding Testing in Pavements. Materials and Structures, 51 (4), article 96.

Petit C., Chabot A., Destree A., Raab C. (2018b). Interface debonding behaviour. In Buttlar W.G., Chabot A., Dave E.V., Petit C., Tebaldi G. (Eds) Mechanisms of Cracking and Debonding in Asphalt and Composite Pavements. Chapter III of the State-of-the-Art Report of the RILEM Technical Committee 241-MCD 
Series, Vol. 28: 103-154, Springer, Cham, ISBN 978-3-319-76848-9, Series ISSN, 2213-204X doi: 10.1007/978-3-319-76849-6_3

Tran Q. D., Chabot A., Ehrlacher A., Tamagny P. (2004, May). A simplified modelling for cracking in pavements. C. Petit, I. Al-Qadi \& A. Millien (Eds), Cracking in Pavements. Proceedings of the 5th Int. RILEM Conf. Cracking in Pavements (Rilem Proceedings, PRO37-PR, pp. 299-306, ISBN 2-912143-47-0). Limoges, France.

Rasmussen R. O., Rozycki D. K. (2004). Thin and Ultra Thin Whitetopping - A synthesis of highway practice, NCHRP Synthesis 338, Transportation Research Board.

Rim C. T. (2013). The development and deployement of online electric vehicules (OLEV), IEEE Energy Conversion Congress and Exposition (ECCE), Denver, CO, USA.

Vandenbossche J., Barman M. (2010). Bonded whitetopping overlay design considerations for prevention of reflection cracking, joint sealing, and the use of dowel bars. Transportation Research Record: Journal of the Transportation Research Board, 2155, 3-11.

\section{Tables}

Table 1. Layer elastic characteristics obtained for the asphalt pavement model with the

\begin{tabular}{cccc} 
M4-5nW & & & \\
\hline Layer i & $e^{\mathrm{i}}(\mathrm{m})$ & $E^{\mathrm{i}}(\mathrm{MPa})$ & $v^{\mathrm{i}}$ \\
\hline Layer 1 & 0.05 & 1000 & 0.35 \\
Layer 2 & 0.07 & 1000 & 0.35 \\
Layer 3 & 0.07 & 1000 & 0.35 \\
Layer 4 & 0.28 & 270 & 0.35
\end{tabular}

\section{Figures}

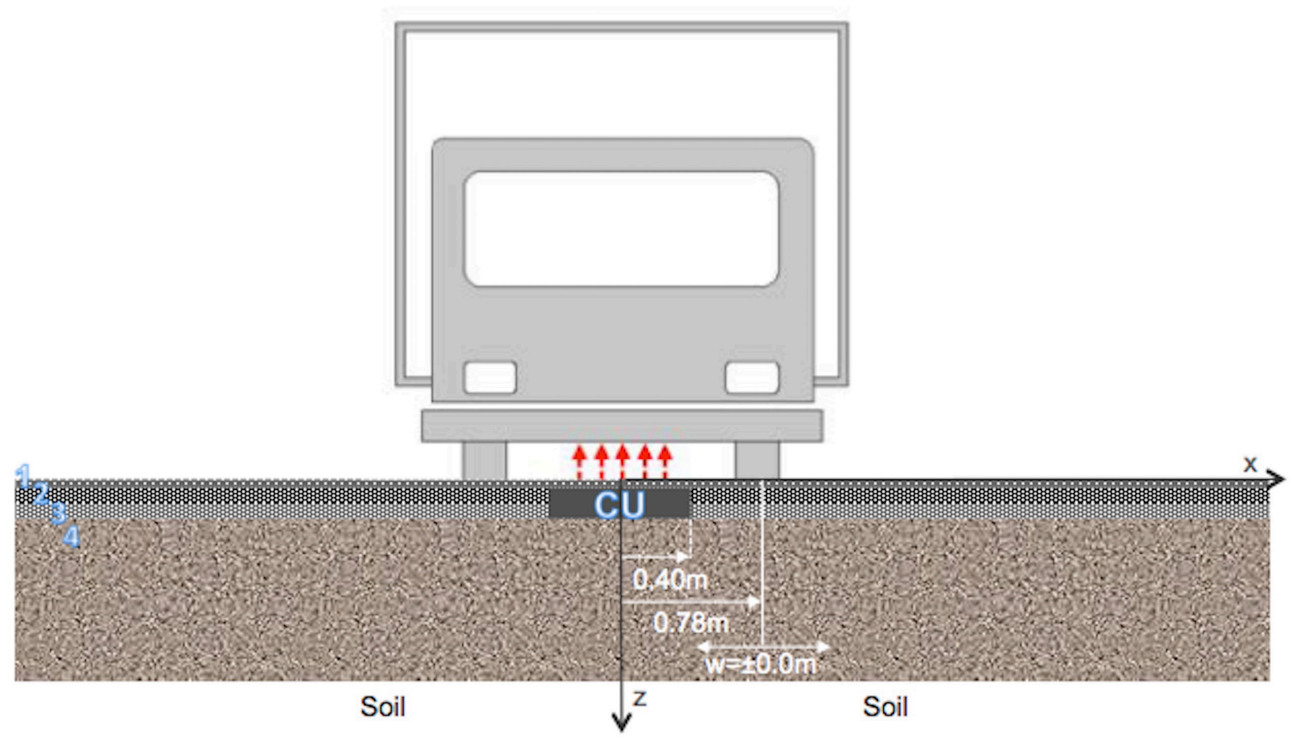

Figure 1. An eRoads example showing the half cross-sectional geometry of an asphalt eRoad with a Charging Unit - CU (according to Chen et al., 2017) 


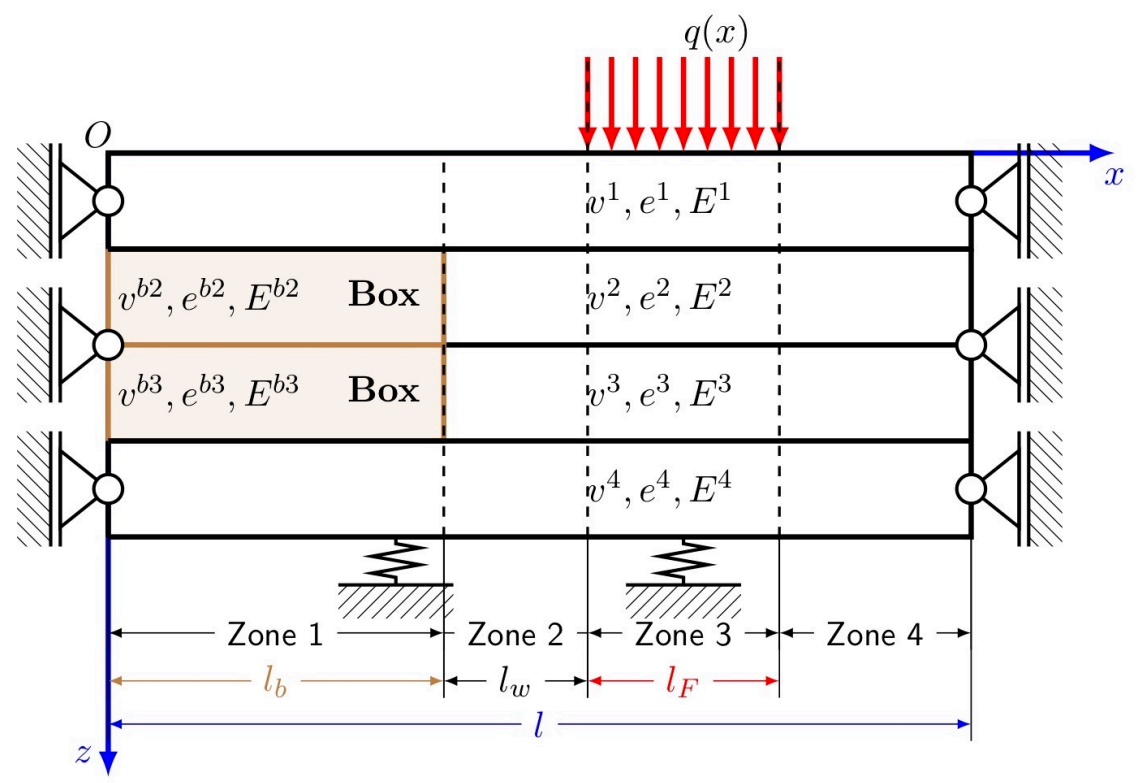

Figure 2. M4-5nW equivalent eRoad model of half the cross-sectional geometry

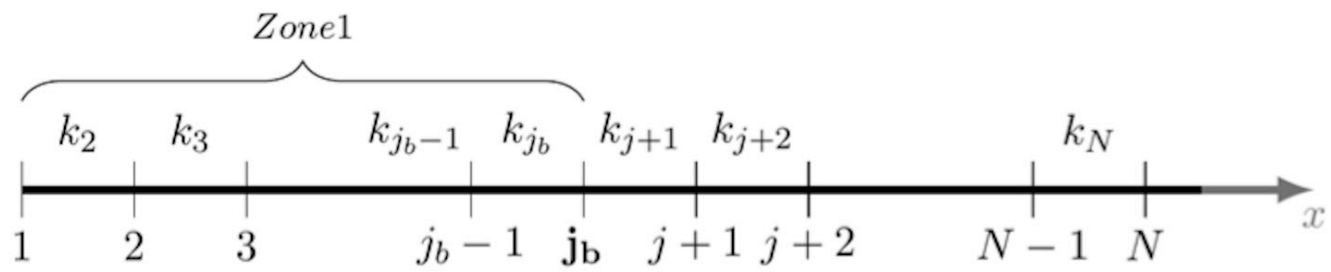

Figure 3. The M4-5nW discretization of the eRoad half cross section

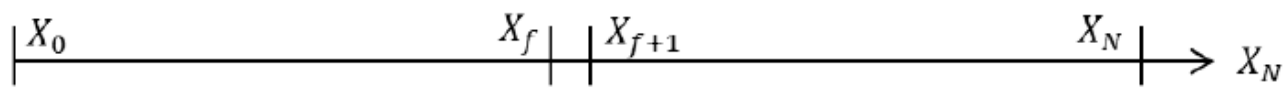

Figure 4. M4-5nW crack discretization of the eRoad half cross section 

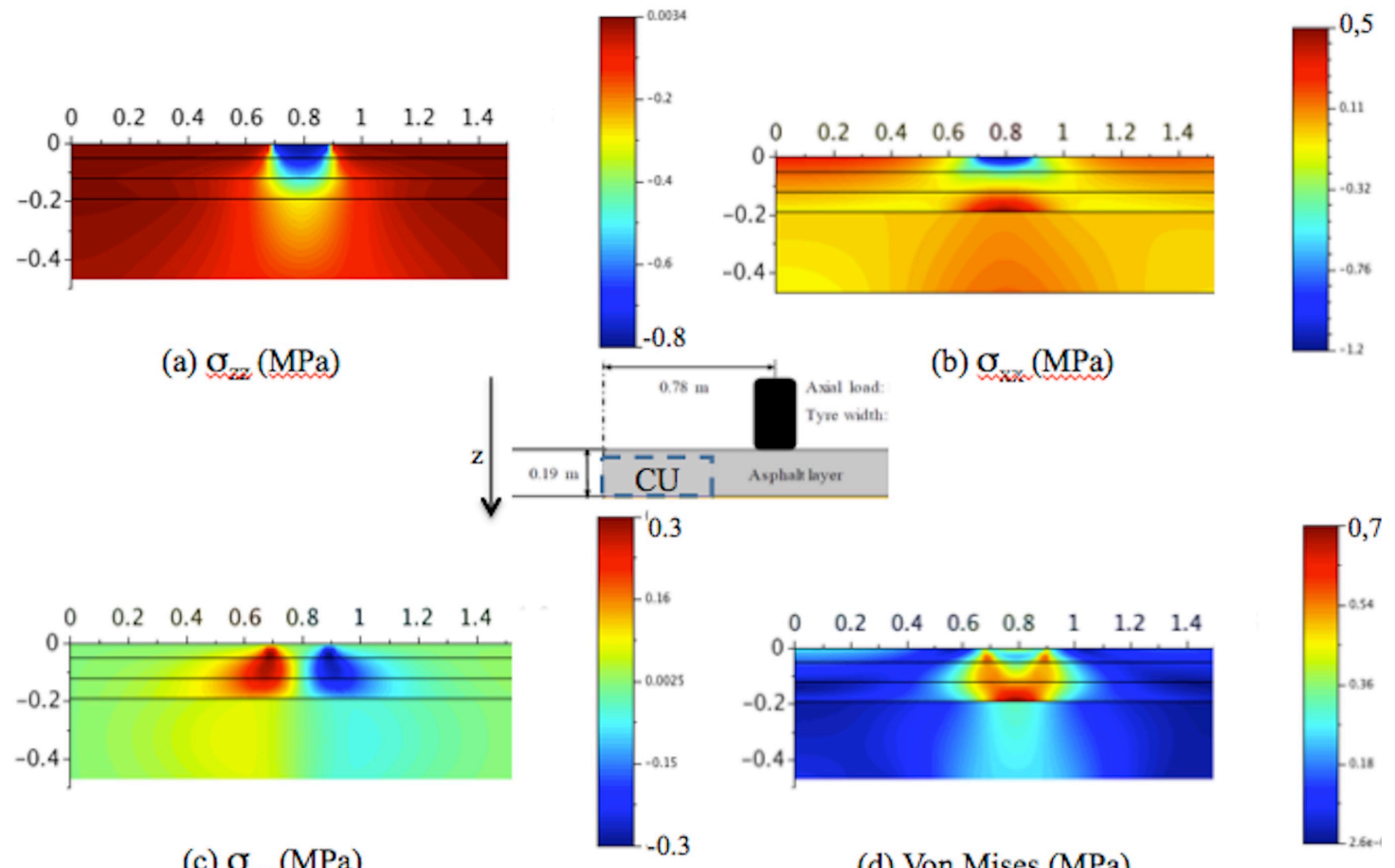

(c) $\sigma_{x z}(\mathrm{MPa})$

(d) Von Mises (MPa)

Figure 5. M4-5nW elastic equivalent results of the asphalt pavement example taken by (Chen et al., 2017) (with Figure 2 configuration)

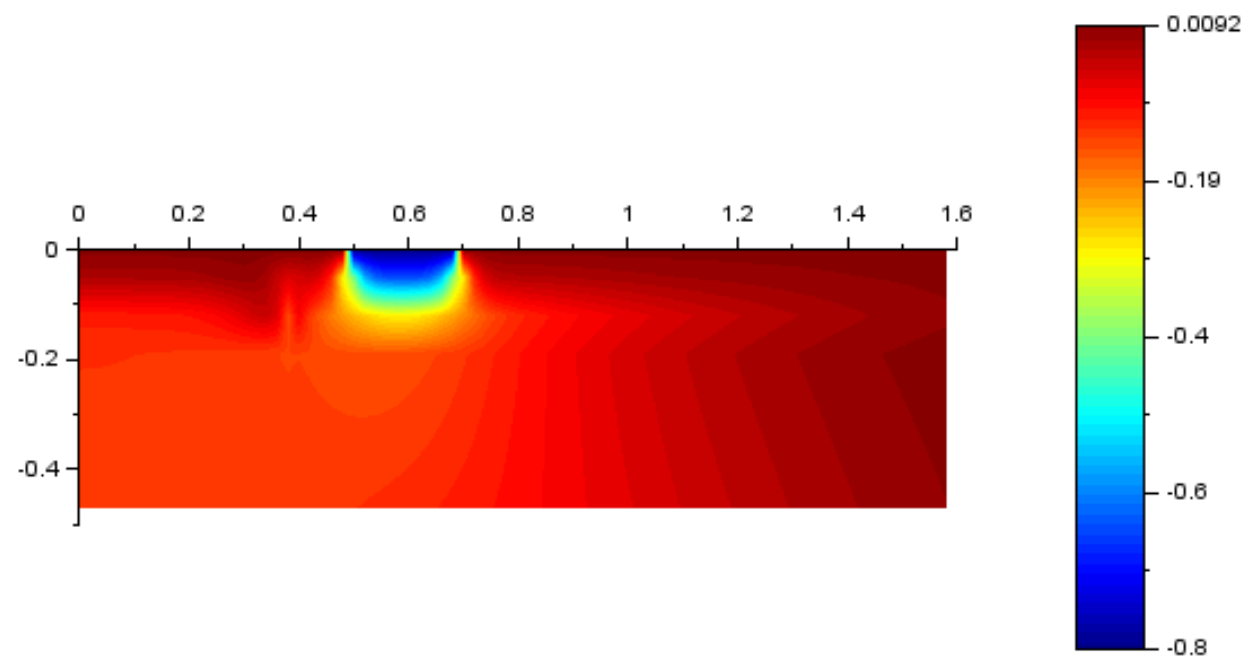

Figure 6. Example of the M4-5nW $\sigma_{z z}$ distribution in the eRoad of Figure 1 with $\mathrm{w}=-0,2$ 


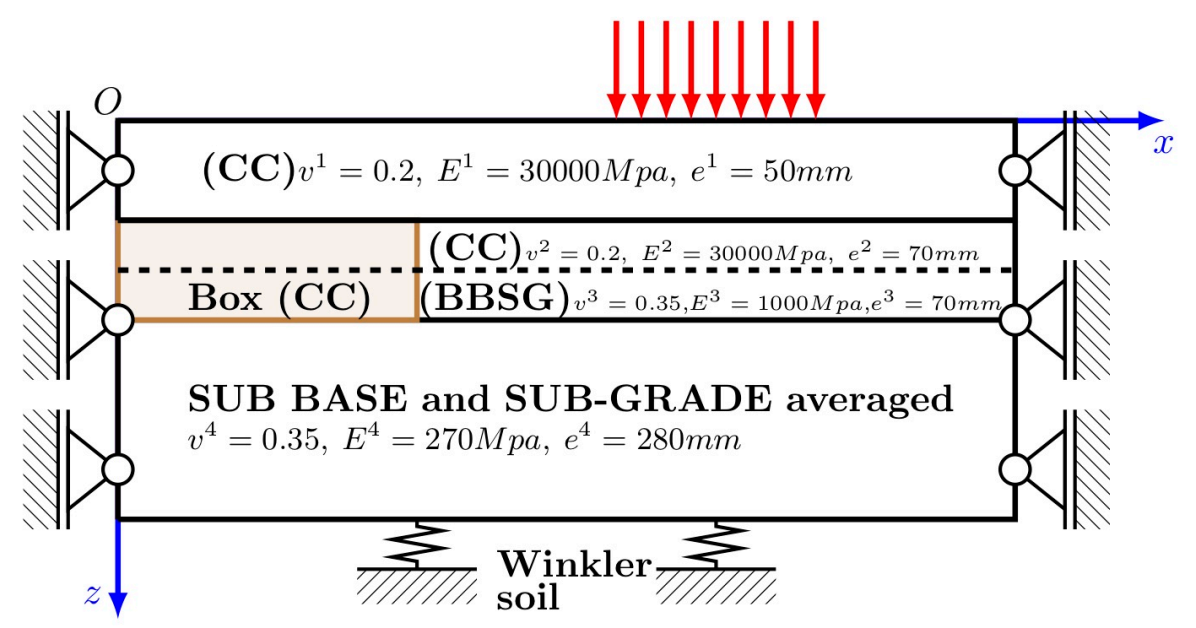

Figure 7. An alternative eRoad pavement structure proposal

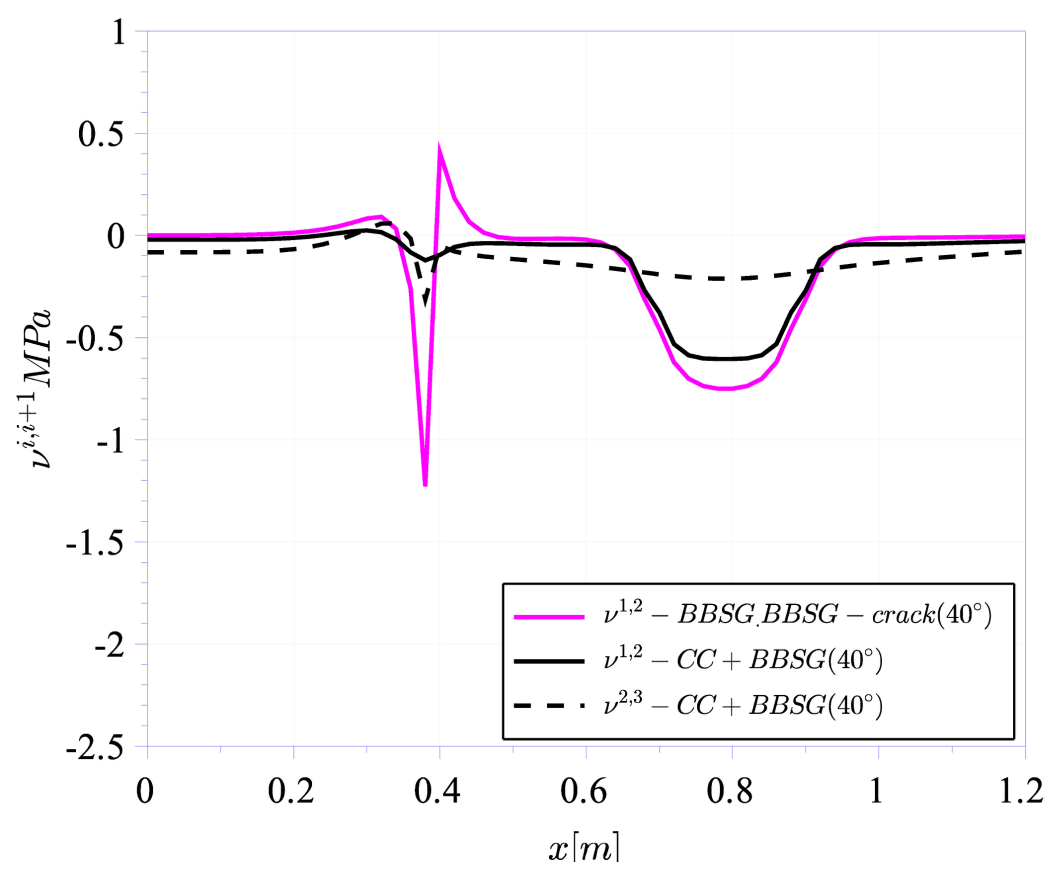

Figure 8. Interfacial normal stress comparison between the various cases $(\mathrm{w}=0.0)$ 


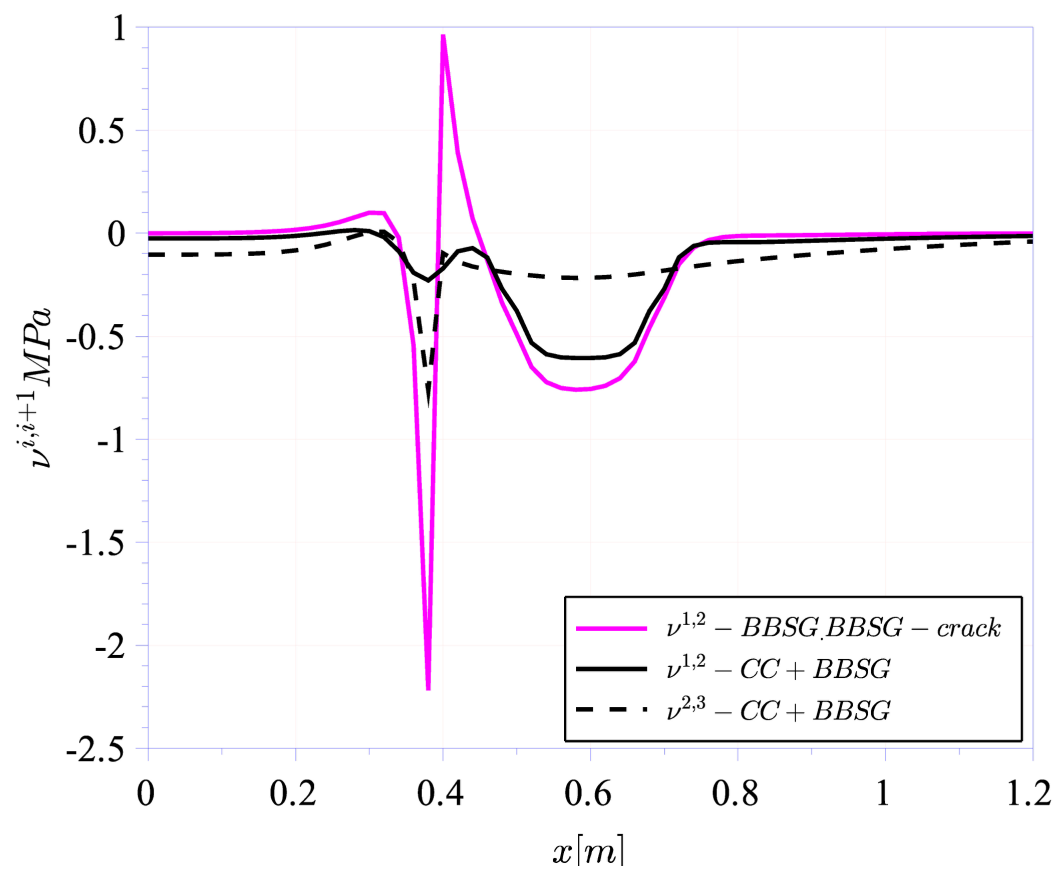

Figure 9. Interfacial normal stress comparison between the various cases $(\mathrm{w}=-0.2)$ 